\title{
The ALERT MDT Field Evaluation Study (AMFES): a descriptive study of leprosy in Ethiopia. Patients, methods and baseline characteristics
}

\author{
PAUL SAUNDERSON*, SHIBRU GEBRE*, \\ KETSELA DESTA* \& PETER BYASS** \\ *ALERT, PO Box 165, Addis Ababa, Ethiopia \\ **School of Community Health Science, Nottingham University, \\ Nottingham, UK and Department of Public Health and Clinical \\ Medicine, Umeå University, Umeå, Sweden
}

Accepted for publication 30 June 2000

\begin{abstract}
Summary The ALERT MDT Field Evaluation Study (AMFES) is a long-term prospective study of 650 patients (594 new cases and 56 relapses after dapsone monotherapy), treated with fixed-duration multiple-drug therapy (MDT), as recommended by WHO. Follow-up has continued for up to 11 years from the start of treatment. This paper presents the methodology of the study and the baseline characteristics of the cohort, while accompanying papers examine the incidence of, and possible risk factors for, the various complications of leprosy, including relapse, reactions and nerve function impairment. The methods of diagnosis, classification and treatment with MDT are described; nerve function was assessed at every visit to the clinic using a standardized methodology, so that reactions and new impairment could be detected early and treated. Eighty-four per cent of new case had at least one thickened nerve, with the ulnar nerve most commonly involved. Seventy-seven per cent of cases completed treatment and only one adverse reaction to the MDT drugs was noted. Twenty-eight per cent of all patients were given steroids at one time or another, almost always for new nerve function impairment, and 3\% of these developed significant complications of steroid treatment. Twenty-nine patients (5\%) received hospital care, including 14 patients who underwent major surgery. Sixty-one per cent of the women over 19 years of age had at least one pregnancy, but pregnancies were much less common after leprosy was diagnosed.
\end{abstract}

\section{Introduction}

The WHO-recommended multi-drug therapy (MDT) for leprosy has proved to be remarkably effective in curing the disease, with very low reported rates of relapse. The complications of

Correspondence to: P. Saunderson, ALM, 1 ALM Way, Greenville SC 29601, USA (e-mail: psaunderson@ leprosy.org) 
leprosy (in particular, reactions and nerve damage) remain, however, as important causes of impairment and disability. Most previous reports of these complications of leprosy have been retrospective studies, so a long-term, prospective study was planned at the All Africa Leprosy, Tuberculosis and Rehabilitation Training Centre (ALERT) in Ethiopia, to characterize more accurately the incidence of, and risk factors for, reactions and nerve function impaiment.

The ALERT MDT Field Evaluation Study (AMFES) was started in 1988 with three main objectives. These were to assess:

1. The incidence of relapse and factors associated with the occurrence of relapse after fixedduration MDT: 6 months treatment for paucibacillary (PB) cases and 24 months for multibacillary (MB) cases;

2. The incidence of leprosy reactions and factors associated with the occurrence of reactions, both during and after MDT; and

3. The incidence of new or increased nerve dysfunction and its progression to permanent nerve function impairment.

In all, 660 patients were enrolled between 1988 and 1993. After release from treatment, active surveillance was carried out. PB patients were followed for 5 years after release from treatment and then discharged, while MB patients have remained on active surveillance. The AMFES project will close at the end of 1999, but it is hoped that a group of $180 \mathrm{MB}$ patients who are still on surveillance, will be reviewed annually for at least a further 5 years to look for late relapses.

The enrolment procedures and the administration of treatment have been described in detail. ${ }^{1}$ In the absence of active case finding, practically all patients enter the control programme as self-reporting new cases. All new, untreated leprosy patients were eligible for enrolment. While that initial paper reported on the first 286 patients enrolled, this paper now reports on the complete cohort of 660 patients. Accompanying papers report the findings in relation to the original objectives of AMFES, building on the interim results reported by de Rijk et al. ${ }^{1,2}$

\section{Materials and methods}

\section{BACKGROUND}

The ALERT leprosy control programme covers an area of $85,000 \mathrm{~km}^{2}$ in central Ethiopia, an area which used to be one province (Shoa) but which is now divided between several new administrative regions. The population has grown from under 11 million in 1988, to over 13 million in 1998. The programme includes the capital city, Addis Ababa, but is otherwise predominantly rural. Travel in more remote parts of the programme area is difficult. AMFES was started in only certain parts of the programme area, because of the difficulty of travel and communication.

The former government of Ethiopia was overthrown in May, 1991, with much civil unrest and insecurity in the period before that date and some disruption of routine services in the period afterwards. Thus it is to the great credit of the field staff of the programme and the patients themselves, that case-holding during those difficult times was maintained at a reasonable level, although the greatest number of losses to follow-up occurred at that time. The staff working in the AMFES project number about 12-15 experienced health assistants and there have been remarkably few staff changes, so that most patients have been reviewed by either one or two individuals throughout the period of treatment and surveillance. 
The ALERT leprosy control programme functioned as a vertical programme throughout the AMFES study period, but is now in the process of being decentralized and integrated into the general health services. As a vertical programme attached to the Training Centre at ALERT, however, it was a useful testing ground for a number of initiatives which have since become standard practice for field programmes; for example, the regular assessment of nerve function and the treatment of neuritis with steroids. ${ }^{3,4}$ More recent initiatives have looked at ways of preventing further disability with protective footwear ${ }^{5}$ and methods of empowering former patients to take responsibility for their own care. The issue of delay in presentation of new leprosy cases has also been investigated in the field programme ${ }^{6}$ and has been reported for the AMFES cohort also. ${ }^{7}$

\section{DIAGNOSIS}

The methods of diagnosis, administration of fixed-duration MDT and case-holding in AMFES have been previously reported ${ }^{1}$ and were essentially the same as in the routine leprosy control programme run by ALERT. The finding of at least one of the three classical cardinal signs of leprosy (loss of sensation in a typical skin patch, thickening of a peripheral nerve or a positive skin smear) was the basis of the diagnosis. Skin smears were done routinely and the bacillary index (BI) and morphological index (MI) were recorded for each of four sites. The patient's BI was taken as the highest of the four readings. Case-finding was generally by voluntary self-reporting and treatment was given through a series of monthly clinics run as a vertical programme.

\section{HISTOLOGY}

Histological services were available at ALERT. Biopsies were taken from $30 \%$ of patients, either because of uncertainty in diagnosis or classification (16\%), or as a random sample to check the clinical diagnosis and classification (14\%).

\section{CLASSIFICATION}

Patients were classified according to the Ridley/Jopling method on clinical grounds, with BB cases being grouped together with BL cases. For the WHO treatment categories, the following definitions were used:

- Paucibacillary (PB) cases are those clinically or histopathologically classified as tuberculoid (TT), borderline tuberculoid (BT) or indeterminate (I), whose highest BI at any site is no more than 1.

- Multibacillary (MB) cases are those clinically or histopathologically classified as borderline lepromatous (BL) or lepromatous (LL) and any others who had a BI of more than 1 at any site.

Soon after the start of the project these definitions were altered so that any patient with a positive skin smear at any site was treated as an MB case. Three cases with a BI of 1 were treated with the PB regimen under the earlier rules; they were not reclassified or retreated. The number of skin lesions and number of nerves involved were not used to classify patients as is currently the case in many programmes, following recent recommendations by $\mathrm{WHO}^{8}$ A large number of the $\mathrm{PB}$ cases in this study would have been 
classified as $\mathrm{MB}$, if the main indicator for being $\mathrm{MB}$ were the presence of more than five lesions.

The term neural leprosy was used for patients with nerve involvement only, indicated by undoubted nerve enlargement, with or without nerve function impairment, but with negative skin smears and no skin lesions. Patients in this group with only one nerve involved were treated with the $\mathrm{PB}$ regimen, while all others received the MB regimen.

\section{SURVEILLANCE AND REVIEW}

During the period of surveillance after treatment, patients were given 6-monthly appointments and were traced by various methods if they failed to attend. These methods included sending a message with other patients, the use of a scout to visit the patient, or a home visit by the health worker. The period of surveillance for PB patients was 5 years, but has been extended for MB patients because of the possibility of relapse in the second 5-year period after release from treatment. There was no active surveillance of non-AMFES patients during this period.

The assessment of patients every month (every 6 months after release from treatment) has also been described in detail ${ }^{2}$ and consisted of a brief history and examination, followed by a standardized nerve function assessment: this included voluntary muscle testing (VMT) and sensory testing (ST) of nerves supplying the eyes, hands and feet. This procedure was also standard practice throughout the ALERT leprosy control programme area. Four muscles were tested for muscle strength: eye closure (facial nerve), abduction of the fifth finger (ulnar nerve), abduction of the thumb (median nerve) and dorsiflexion of the foot (peroneal nerve); a three-point scale was used to record the results, each muscle being graded as strong (S), weak (W) or paralysed (P). Sensory testing involved testing 10 sites on the palm of each hand and the sole of each foot with a $10 \mathrm{~g}$ nylon monofilament; at each of the 40 points the monofilament was recorded as either 'felt' or 'not felt'.

IMPAIRMENT AND DISABILITY

The details of the examination were recorded each time on the patient's record card. The WHO Disability Grades, more correctly referred to as Impairment Grades, ${ }^{9}$ were also recorded for each examination. For the purpose of analysis they have been tabulated at the start of treatment, at release from treatment and 5 years after release from treatment. De Rijk et al. proposed a simple summation score of WHO grades ${ }^{1}$ and this has been refined into the 'EHF' score, which is becoming more widely used to monitor groups of patients over time.' The EHF score (the Eye-Hand-Foot score, which is the sum of all six WHO Grades) can be calculated from the Impairment Grades and these scores have been tabulated at the same stages of the disease as the WHO Grades.

\section{EVENTS}

At each review, the main outcome was the presence or absence of a nevent. Four categories of event are recognized:

1. Reversal or type 1 reaction.

2. Erythema nodosum leprosum (ENL) or type 2 reaction.

3. Neuritis and new nerve function impairment (grouped together as neuropathy).

4. Relapse. 
Reactions were diagnosed according to the history and clinical examination of the skin. Reversal reactions were diagnosed when there were symptoms and signs of inflammation in the leprosy skin lesions; no distinction was made between upgrading and downgrading reactions. Erythema nodosum leprosum was diagnosed when the typical red and painful nodules of the condition were seen.

New nerve function impairment and neuritis were recorded as one category (neuropathy), as they were considered to reflect different degrees of the same pathological process and were managed in the same way. Neuritis, or inflammation of a nerve, is indicated by pain or tenderness in the nerve, with or without loss of function. New nerve function impairment is indicated by a deterioration in the results of voluntary muscle testing and/or sensory testing: any recent loss of muscle strength (a change from ' $\mathrm{S}$ ' to ' $\mathrm{W}$ ' or from ' $\mathrm{W}$ ' to ' $\mathrm{P}$ ' or from ' $\mathrm{S}$ ' to ' $\mathrm{P}$ ' in any muscle) shows new impairment, and a recent loss of at least two points of sensation also shows new impairment; if the symptoms and signs of nerve involvement are of less than 6 months duration, the event is referred to as an episode of acute neuropathy. Neuritis and new nerve function impairment of ten occur with reactions, but may also occur alone; new nerve function impairment without accompanying symptoms of a reaction and without nerve pain, is referred to as silent neuropathy. ${ }^{10}$

Many patients have repeated events. There are as yet no strict definitions of the terms 'chronic' and 'recurrent' as applied to reactions and neuropathy in leprosy, although the terms are used. For this series of reports on the AMFES cohort, an event is said to be chronic if it recurs within 3 months of stopping treatment (usually steroids), or if the standard course of steroids has to be prolonged because of continuing signs and symptoms. Recurrent events are those events that recur after a gap of at least 3 months, during which the patient has no symptoms of reaction or neuritis and is not being treated with any anti-reaction medication.

\section{MANAGEMENT OF EVENTS}

Mild reactions of both types are defined as those involving only the skin, without any neuritis or nerve function impairment; they are treated symptomatically with aspirin. Severe reversal reactions have skin signs and new nerve function impairment and are treated with a course of steroids - prednisolone can be prescribed in the leprosy clinic, according to clear guidelines and with appropriate safeguards. ${ }^{411}$ If new nerve function impairment is detected within 6 months, there is a strong possibility of reversing some or all of the damage with steroids. ${ }^{12}$ Patients who require steroids but who have a contraindication to steroid treatment should be referred to ALERT hospital.

Severe ENL reactions are those with new nerve function impairment and/or involvement of other organs, such as the eyes (irido-cyclitis), testes (orchitis) or fingers (dactylitis), with fever and general malaise. These cases should be referred to ALERT hospital, because of the chronic and debilitating nature of the condition, the need for further investigations and the need for prolonged treatment (perhaps including admission) in many cases.

Suspected relapses require thorough investigation and should be referred to ALERT. The results of such investigations carried out to date are reported elsewhere.

\section{RECORDS}

Data management and analysis has been carried out throughout the study period. Patient record cards were regularly submitted to the statistical unit for data entry. Quality control 
Table 1. The classification of AMFES patients

\begin{tabular}{lccrcrrr}
\hline R/J classification & \multicolumn{3}{c}{ New cases } & & \multicolumn{3}{c}{ Relapse cases } \\
& PB & MB & Total & PB & MB & Total & $\begin{array}{c}\text { Grand } \\
\text { total }\end{array}$ \\
\hline TT & 6 & - & 6 & - & - & - & 6 \\
BT & 287 & 12 & 299 & 3 & 1 & 4 & 303 \\
BL & - & 202 & 202 & - & 41 & 41 & 243 \\
LL & - & 84 & 84 & - & 11 & 11 & 95 \\
Neural leprosy & 1 & 2 & 3 & - & - & - & 3 \\
Total & 294 & 300 & 594 & 3 & 53 & 56 & 650 \\
\hline
\end{tabular}

took place at various levels: medical officers checked the patient records for consistency and a number of manoeuvres to check the internal consistency of the database were carried out; finally, unresolved inconsistencies and missing data were discussed and checked by reference to the original record card or by asking the patient directly, if possible.

Data entry and management used dBase software, while analysis has largely been done using EpiInfo v6, Excel v5 and Egret software.

\section{Results}

\section{DIAGNOSIS}

A total of 660 patients were enrolled and there were 10 exclusions. The reasons for exclusion were: incorrect enrolment procedures (five cases) and incorrect diagnosis (five cases). The five cases with an incorrect diagnosis included cases of granuloma annulare, chronic non-specific dermatitis, secondary syphilis and onchodermatitis, all diagnosed histologically; one case was not biopsied but the diagnosis of leprosy was ruled out by the medical of ficer on clinical grounds. On reviewing the record card, it was concluded that the case with onchodermatitis may have had leprosy as well, but he had completed PB-MDT before being discharged.

Of the remaining 650 cases, 594 were new cases and 56 were patients previously treated with dapsone monotherapy, presenting as relapses. The new cases had sometimes had a few doses of dapsone prior to starting MDT, but this was less than 8 weeks treatment for PB cases and less than 16 weeks for MB cases.

The new patients included in the AMFES cohort have been compared with the other new cases started on MDT during the same period in the routine programme of ALERT, with regard to age, sex, classification and impairment status at diagnosis. No important differences were observed and the AMFES patients are thus regarded as representative of all new cases detected in the area during the same period. ${ }^{7}$

Table 2. Number of skin lesions in new PB cases

\begin{tabular}{lrcccc}
\hline & N & $\begin{array}{c}\text { Number with } \\
1-5 \text { lesions }\end{array}$ & $\begin{array}{c}\text { Number with } \\
\text { 6-19 lesions }\end{array}$ & $\begin{array}{c}\text { Number with 20 } \\
\text { or more lesions }\end{array}$ & Unknown \\
\hline TT cases & 6 & 6 & - & - & - \\
BT cases & 287 & 81 & 150 & 50 & 6 \\
Total & 293 & 87 & 150 & 50 & 6 \\
\hline
\end{tabular}


Table 3. Impairment of individual nerves at diagnosis

\begin{tabular}{|c|c|c|c|c|c|c|c|}
\hline \multirow[b]{2}{*}{ Nerve } & \multirow[b]{2}{*}{ Modality } & \multicolumn{2}{|c|}{$\begin{array}{l}\text { Patients with } 1-5 \\
\text { lesions }(n=87)\end{array}$} & \multicolumn{2}{|c|}{$\begin{array}{l}\text { All PB patients } \\
(n=294)\end{array}$} & \multicolumn{2}{|c|}{$\begin{array}{c}\text { MB patients } \\
(n=300)\end{array}$} \\
\hline & & Number & Percent & Number & Percent & Number & Percent \\
\hline \multirow[t]{3}{*}{ Ulnar } & Sensory & 11 & 13 & 68 & 23 & 71 & 24 \\
\hline & Motor & 8 & 9 & 66 & 22 & 84 & 28 \\
\hline & Both & 6 & 7 & 51 & 17 & 49 & 16 \\
\hline \multirow[t]{3}{*}{ Median } & Sensory & 9 & 10 & 66 & 22 & 64 & 21 \\
\hline & Motor & 3 & 3 & 29 & 10 & 24 & 8 \\
\hline & Both & 3 & 3 & 25 & 9 & 19 & 6 \\
\hline Facial & Motor & 2 & 2 & 20 & 7 & 22 & 7 \\
\hline Post. Tib & Sensory & 28 & 32 & 131 & 45 & 164 & 55 \\
\hline Peroneal & Motor & 0 & 0 & 15 & 5 & 10 & 3 \\
\hline
\end{tabular}

\section{CLASSIFICATION}

The classification of the AMFES patients is shown in Table 1. There were no indeterminate cases. Table 2 shows the number of skin lesions seen in PB cases and thus how they may be classified according to current recommendations.

\section{NERVE INVOLVEMENT AT DIAGNOSIS}

Thickened nerves are one of the cardinal signs of leprosy. Of 594 new cases, 496 (84\%) had thickened nerves. The ulnar nerve was most commonly involved (403 cases), followed by the radial cutaneous nerve.

Impairment at diagnosis is examined more fully in a separate report ${ }^{7}$ where it is shown that delay in diagnosis is strongly associated with impairment. Impairment related to individual nerves is shown in Table 3 .

\section{TREATMENT}

Table 4 shows the results of treatment for all 650 cases. Seventy-seven per cent of all patients completed treatment ( $83 \%$ for PB cases and $73 \%$ for MB cases). There were five additional deaths after completion of 5 years surveillance that are known of.

Table 4. Results of treatment of AMFES patients

\begin{tabular}{|c|c|c|c|c|c|c|c|}
\hline \multirow[b]{2}{*}{ Status } & \multicolumn{3}{|c|}{ New cases } & \multicolumn{3}{|c|}{ Relapse cases } & \multirow{2}{*}{$\begin{array}{c}\text { Grand } \\
\text { total }\end{array}$} \\
\hline & PB & MB & Total & PB & $\mathrm{MB}$ & Total & \\
\hline Enrolled & 294 & 300 & 594 & 3 & 53 & 56 & 650 \\
\hline Transferred out & - & 1 & 1 & - & - & - & 1 \\
\hline Died during treatment & 1 & 12 & 13 & - & 2 & 2 & 15 \\
\hline Treatment not completed & 50 & 75 & 125 & - & 7 & 7 & 132 \\
\hline Released from treatment & 243 & 212 & 455 & 3 & 44 & 47 & 502 \\
\hline Died during follow-up & 11 & 7 & 18 & - & - & - & 18 \\
\hline Incomplete follow-up & 109 & 22 & 131 & - & - & - & 131 \\
\hline Discharged after 5 years & 123 & 46 & 169 & 3 & 1 & 4 & 173 \\
\hline Continuing follow-up & - & 137 & 137 & - & 43 & 43 & 180 \\
\hline
\end{tabular}


Table 5. Baseline characteristics of patients in relation to treatment completion

\begin{tabular}{|c|c|c|c|c|c|}
\hline & Variables & $\begin{array}{l}\text { Number (\%) of } \\
\text { enrolled patients }\end{array}$ & $\begin{array}{l}\text { Number (\%) who } \\
\text { completed treatment }\end{array}$ & $\begin{array}{l}\text { Number }(\%) \text { who did not } \\
\text { complete treatment }\end{array}$ & $\begin{array}{c}\text { Number }(\%) \text { who died } \\
\text { during treatment }\end{array}$ \\
\hline Number & $(n)$ & $650(100)$ & $502(77)$ & $132(21)$ & $15(2)$ \\
\hline \multirow[t]{2}{*}{ Sex: } & Male & $415(64)$ & $322(78)$ & $81(19)$ & $11(3)$ \\
\hline & Female & $235(36)$ & $180(76)$ & $51(22)$ & $4(2)$ \\
\hline \multirow[t]{3}{*}{ Age } & up to 19 years & $177(27)$ & $146(82)$ & $30(17)$ & - \\
\hline & $20-49$ years & $361(56)$ & $275(76)$ & $77(21)$ & $9(3)$ \\
\hline & 50 and over & $112(17)$ & 81 (72) & $25(22)$ & $6(6)$ \\
\hline \multirow[t]{5}{*}{ Classification } & TT & $6(1)$ & $5(83)$ & $1(17)$ & - \\
\hline & BT & $303(46.5)$ & $251(83)$ & 50 (19) & $2(1)$ \\
\hline & $\mathrm{BL}$ & $243(37.5)$ & $171(71)$ & $61(25)$ & $10(4)$ \\
\hline & LL & $95(14.5)$ & 73 (77) & $19(20)$ & $3(3)$ \\
\hline & Neural & $3(0.5)$ & 2 (67) & $1(33)$ & - \\
\hline \multirow{3}{*}{$\begin{array}{l}\text { Impairment } \\
\text { at start }\end{array}$} & WHO grade 0 & $272(42)$ & $211(78)$ & $57(21)$ & $4(1)$ \\
\hline & WHO grade 1 & $200(31)$ & $153(77)$ & $44(22)$ & $3(1)$ \\
\hline & WHO grade 2 & $178(27)$ & $138(78)$ & $31(17)$ & $8(5)$ \\
\hline \multirow{3}{*}{$\begin{array}{l}\text { EHF score } \\
\text { at start }\end{array}$} & $<2$ & $316(48.5)$ & 244 (77) & $68(22)$ & $4(1)$ \\
\hline & $2-4$ & $245(37.5)$ & $185(76)$ & $52(21)$ & $7(3)$ \\
\hline & $>4$ & 89 (13) & $73(82)$ & $12(15)$ & $4(5)$ \\
\hline
\end{tabular}


Table 6. The prescription of steroids in relation to classification.

\begin{tabular}{lccc}
\hline R/J Classification & Number of cases & $\begin{array}{c}\text { Number given } \\
\text { steroids at any time }\end{array}$ & Percent \\
\hline TT & 6 & 0 & 0 \\
BT & 303 & 60 & 20 \\
BL & 243 & 94 & 39 \\
LL & 95 & 30 & 32 \\
Neural leprosy & 3 & 1 & 33 \\
Total & 650 & 185 & 28 \\
\end{tabular}

The drugs used to treat leprosy were very well tolerated. Only one drug-related problem arose: a 15-year-old female, HIV-negative patient with BL leprosy developed an allergy to dapsone, which was confirmed in hospital with a later challenge dose. The allergy took the form of an exfoliative dermatitis and started during the second month of MDT. The patient continued treatment with two drugs, rifampicin and clofazimine, for 2 years.

Table 5 shows baseline data for all 650 AMFES patients and compares the baseline characteristics of those who completed treatment with those who did not.

Of the $50 \mathrm{~PB}$ patients who did not complete MDT, 31 (62\%) received more than two doses of MDT and of the $82 \mathrm{MB}$ patients not completing treatment, 35 (43\%) received 12 or more doses of MDT.

\section{USE OF STEROIDS}

In all, $185(28 \%)$ of the 650 patients in AMFES were treated with steroids at one time or another, almost always for new nerve function impairment. Table 6 shows the need for steroids according to classification.

Steroids were generally well tolerated, but $5(3 \%)$ of the 185 patients did have serious complications; all five were multibacillary cases. One had an acute fever possibly due to typhoid after a short course of steroids. The other four had all had prolonged courses of steroids for chronic events and developed foot sepsis/osteomyelitis (two cases), tuberculosis (one case) or pre-senile cataracts (one case).

\section{HOSPITAL RECORDS AND SURGERY}

Fifty-seven (9\%) of the 650 AMFES patients have ALERT hospital records, but half of these (28 cases) were seen only for diagnosis and did not require admission or further specialist attention. Twenty-nine cases $(4.5 \%)$ have been followed up more intensively by the hospital, with regular outpatient reviews and/or periods of in-patient care. Fourteen cases had major surgery (excluding basic septic surgery): this included $13(2.2 \%)$ of the 594 new cases in the study and one further patient refused surgery (an ulnar nerve release). Nerve release surgery was carried out on four patients and reconstructive surgery on six patients.

\section{PREGNANCY}

The timing of deliveries was recorded in order to assess the status of pregnancy as a risk factor for events in female patients. Of the 235 women enrolled, $156(67 \%)$ were over 19 
years at diagnosis. Ninety-five (61\% of those over 19 years) had had at least one pregnancy. There were 14 deliveries in the 6 months before leprosy was diagnosed, giving an incidence of 23 per 100 person-years-at-risk (14 deliveries in 124 women currently of child-bearing age, observed for 6 months). No control group was studied but this is a typical figure for women in the region at that time. ${ }^{13}$ There were far fewer pregnancies in the AMFES women after the diagnosis of leprosy.

\section{Discussion}

AMFES has provided an unusual opportunity to follow a large cohort of leprosy patients over a long period. The main objectives are to establish the relapse rate after fixed-duration MDT and to elucidate the natural history of reactions and nerve damage, especially in the period after the completion of MDT, when medical care may be much less accessible for many patients.

Ethiopia is a large country with a prevalence of leprosy of around 1 per 10,000 population, putting it amongst the 10 countries with the most leprosy, in terms of case numbers. MDT is well established but stigma remains a major obstacle to good leprosy control. $^{6}$

There is wide variation in the characteristics of new cases of leprosy around the world, in terms of disease classification and impairment status at diagnosis. In South Asia there tends to be a predominance of PB disease: for example, $83 \%$ of cases in Bangladesh ${ }^{14}$ and $66 \%$ of cases in Thailand. ${ }^{15}$ In other countries, such as Indonesia, the Philippines and Brazil there tends to be a much higher percentage of MB cases. ${ }^{16}$ The mix of cases in Africa is perhaps more variable, reflecting greater variation in case-finding activities, but the AMFES cohort with $50 \%$ of cases being MB may be regarded as fairly typical. The AMFES patients have a generally higher rate of disability at diagnosis than is reported elsewhere. There are several possible explanations for this, including the length of delay in being diagnosed and the routine use of the $10 \mathrm{~g}$ monofilament for sensory testing; this is a sensitive instrument and may allow the finding of more loss of sensation than other routine methods, such as the ballpoint pen. There has been considerable debate over the normal thresholds for sensation in the hand and foot, and what the implications are for the diagnosis of impairment in leprosy. ${ }^{17,18}$ The $10 \mathrm{~g}$ monofilament may be too sensitive for the foot in many situations and may have led to the overdiagnosis of sensory loss in some cases. Some referral centres use graded monofilaments to determine the level of sensory loss, but as almost all the nerve function assessments in this study were done under field conditions, this more sophisticated method was not used.

The commonest impairment in the AMFES cohort was loss of sensation in the sole of the foot, found in about half of all patients. About one-quarter of all patients had ulnar nerve function impairment, with sensation and muscle strength affected equally. With the median nerve, sensory loss is more common than loss of muscle strength. These findings are similar those reported from Bangladesh, although the overall rate of impairment in that study is much less. $^{14}$

MDT is very well tolerated and only one adverse reaction was noted in the AMFES cohort, namely an allergic reaction to dapsone. Steroids were used in over a quarter of all cases at one time or another. Complications of steroid use were almost entirely confined to those patients given prolonged courses, although this could be related to better 
record-keeping: patients given prolonged courses of steroids would be under a hospital consultant and have more detailed hospital records.

There is very little literature on the effect of pregnancy on leprosy and its complications, although some studies suggest that new leprosy cases present more commonly either during pregnancy or soon afterwards. ${ }^{19}$ The results reported here show that pregnancy and delivery were much more common in the 6 months before diagnosis than in the years after diagnosis. There are many possible confounding factors, but a comparison with figures for women without leprosy in the region suggests that a reduced incidence of pregnancy after the diagnosis has been made, is the more significant finding. A number of possible social factors could be proposed to account for this, such as divorce or a reduced possibility of marriage.

In conclusion, the AMFES project involves a cohort of leprosy patients with severe disease, manifested by a high MB rate, a high rate of smear positivity and a high degree of nerve involvement. The incidence of and risk factors for further nerve damage and disability, as well as leprosy relapses, will be examined in subsequent papers.

\section{Acknowledgements}

We thank the staff of the ALERT Leprosy/TB Control Division for their dedication and perseverance in managing the patients and collecting data over so many years. The financial support of ILEP, through Netherlands Leprosy Relief (NLR), has been constant throughout the 12 years of the study and is gratefully acknowledged. We also thank ALERT as a whole for institutional and administrative support.

\section{References}

${ }^{1}$ de Rijk A J, Gebre S, Byass P, Berhanu T. Field evaluation of WHO-MDT of fixed duration at ALERT, Ethiopia: the AMFES project, part 1. MDT course completion, case-holding and another score for disability grading. Lepr Rev, 1994; 65: 305-319.

2 de Rijk A J, Gebre S, Byass P, Berhanu T. Field evaluation of WHO-MDT of fixed duration, at ALERT, Ethiopia: the AMFES project, part 2. Reactions and neuritis during and after MDT in PB and MB leprosy patients. Le pr Rev, 1994; 65: 320-332.

3 de Rijk A J, Byass P. Field comparison of 10-g and 1-g filaments for the sensory testing of hands in Ethiopian leprosy patients. Lepr Rev, 1994; 65: 333-340.

4 Becx-Bleumink M, Berhe D, t'Mannetje W. The management of nerve damage in the leprosy control services. Lepr Rev, 1990; 61: 1-11.

5 Seboka G and Saunderson PR. Cost-effective footwear for leprosy control programmes: a study in rural Ethiopia. Lepr Rev, 1996; 67: 208-216.

6 Bekri W, Gebre S, Mengiste A et al. Delay in presentation and start of treatment in leprosy patients: a case-control study of disabled and non-disabled patients in three different settings in Ethiopia. Int J Lepr, 1998; 66: 1-9.

7 Meima A, Saunderson PR, Gebre S et al. Factors associated with impairments in new leprosy patients: the AMFES cohort. Lepr Rev, 1999; 70: 189-203.

8 WHO Expert Committee on Leprosy. Seventh Report. WHO Technical Report Series No. 874. WHO, Geneva, 1998.

9 van Brakel WH, Reed NK, Reed DS. Grading impairment in leprosy. Lepr Rev, 1999; 70: 180-188.

10 van Brakel WH, Khawas IB. Silent neuropathy in leprosy: an epidemiological description. Lepr Rev, $1994 ; 65$ : 350-360.

11 Rose P, Waters MF. Reversal reactions in leprosy and their management. Lepr Rev, 1991; 62: 113-121.

12 Saunderson PR, H/Mariam N. Monitoring steroid use in leprosy programmes: possible process indicators. Int $J$ Lepr, 1997; 65: 217-223.

13 United Nations. Demographic Yearbook 1994. New York 1996.

${ }^{14}$ Croft RP, Richardus JH, Nicholls PG, Smith WC. Nerve function impairment in leprosy: design, methodology and 
intake status of a prospective cohort study of 2664 new leprosy cases in Bangladesh (The Bangladesh Acute Nerve Damage Study). Lepr Rev, 1999; 70: 140-159.

15 Schreuder PA. The occurrence of reactions and impairments in leprosy: experience in the leprosy control program of three provinces in northeastern Thailand, 1978-1995. III. Neural and other impairments. Int J Lepr, 1998; 66: 170-181.

16 WHO. Progress towards leprosy elimination. WER, 1998; 73: 153-160.

17 Kets CM, van Leerdam ME, van Brakel WH et al. Reference values for touch sensibility thresholds in healthy Nepalese volunteers. Lepr Rev, 1996; 67: 28-38.

18 Saunderson PR, Gebre S, Currie H, Byass P. Sensory testing of the hand in leprosy (Letter). Lepr Rev, 1997; 68: 252-254.

19 Lockwood DNJ, Sinha HH. Pregnancy and leprosy: a comprehensive literature review.Int J Lepr, 1999; 67: 6-12. 